\title{
Further Understanding of Deformation Safety Monitoring Index of Concrete Arch Dams
}

\author{
Yanchang $\mathrm{Gu}^{1,2, \mathrm{a}}$, Yu Wang ${ }^{1, \mathrm{~b}}$, Qiong Pang ${ }^{1, \mathrm{c}}$ and Yunxing $\mathrm{Wu}^{1, \mathrm{~d}}$ \\ ${ }^{1}$ Nanjing Hydraulic Research Institute, Nanjing, China \\ ${ }^{2}$ Dam Safety Management Center of the Ministry of Water Resources, Nanjing, China \\ a_ruby@126.com, b wangyu1987710@aliyun.com, ${ }^{\text {c }}$ pqnhri@126.com, ${ }^{d}$ fogcloudstar@sina.com
}

Keywords: deformation, safety monitoring, arch dams, hydropower station, early-warning

Abstract. Based on the analysis of deformation characteristics of arch dams of LiJiaxia hydropower station, Dong Jian hydropower station and Feng Le reservoir, the deformation laws are acquired, and the further understandings of deformation safety monitoring index under different conditions are provided to monitor important parts instead of all the sites, which avoid the waste of monitoring resource and improve the early-warning efficiency.

\section{Introduction}

As we all know that concrete dams break in a sudden, if the one in one thousand chance of a dam collapse occurred, the millions of people who live downstream would be endangered. There are three world-shaking events of concrete dams collapse in 20th century, that is, St.Francis dam breach in 1928 in America, Malpasset dam breach in 1954 in France and Vajont dam breach in 1963 in Italy. There is no directed early-warning index in such breach events. Some anomalies could not be found and diagnosed without any early warning criterion even if dam safety monitoring facilities are established. Conversely, an early warning criterion or index of Fozi-Lin dam in China is effectively set to monitor dams' risk and avoid dam breaches. Therefore, an early warning criterion of concrete dam is essential to set in order to monitor dam operation in real time. In addition, the operation performance of concrete dam mainly reflects in the deformation, stress and strain and seepage, and the deformation is the most reliable and direct index of early warning and monitoring.

The determination of concrete dam safety monitoring index was widely studied in China. The principles and methods of determination of the performance index were provided by analyzing dam monitoring data. The determined deformation methods of dam body and foundation includes confidence region method, little probability method of the typical monitoring effect value, limit state method, the simulation calculation method and mechanical calculation method.

However, traditional deformation index is generally based on all the monitoring sites of model, which not only wastes monitoring time and money, but also reduces the early-warning efficiency. In this paper, based on the analysis of deformation characteristics of three typical arch dams, the deformation principle was acquired, and the further understandings of deformation safety monitoring index under different conditions were provided to monitor important parts instead of all the sites, which avoided the waste of monitoring resource and improved the early-warning efficiency.

\section{Typical concrete dams}

Lijia Xia arch dam in Qinhai province, Dongjian arch dam in Hunan province and Fengle arch dam in Anhui province were selected to analyze deformation characteristics on behalf of general concrete arch dams. The fundamental parameters of the dams were shown in Table 1. 
Table 1. Typical concrete arch dams in China

\begin{tabular}{cccccc}
\hline Project name & $\begin{array}{c}\text { Crest } \\
\text { elevation } \\
(\mathbf{m})\end{array}$ & $\begin{array}{c}\text { Dam height } \\
(\mathbf{m})\end{array}$ & $\begin{array}{c}\text { Thickness-height } \\
\text { ratio }\end{array}$ & $\begin{array}{c}\text { Total storage } \\
\text { capacity } \\
\left(\times \mathbf{1 0}^{\mathbf{8}} \mathbf{~ m}^{\mathbf{3}}\right)\end{array}$ & Province \\
\hline $\begin{array}{c}\text { LiJiaxia hydropower } \\
\text { station }\end{array}$ & 2185.00 & 155 & 0.29 & 16.5 & Qinhai \\
\hline $\begin{array}{c}\text { DongJian hydropower } \\
\text { station }\end{array}$ & 294.00 & 157 & 0.22 & 91.5 & Hunan \\
\hline FengLe Reservoir & 211.60 & 54 & 0.23 & 0.84 & Anhui \\
\hline
\end{tabular}

\section{Deformation characteristics of LiJiaxia hydropower station}

There are three vertical lines to monitor deformation in the dam body of LiJiaxia hydropower station, the survey points distribution is shown in Figure 1.

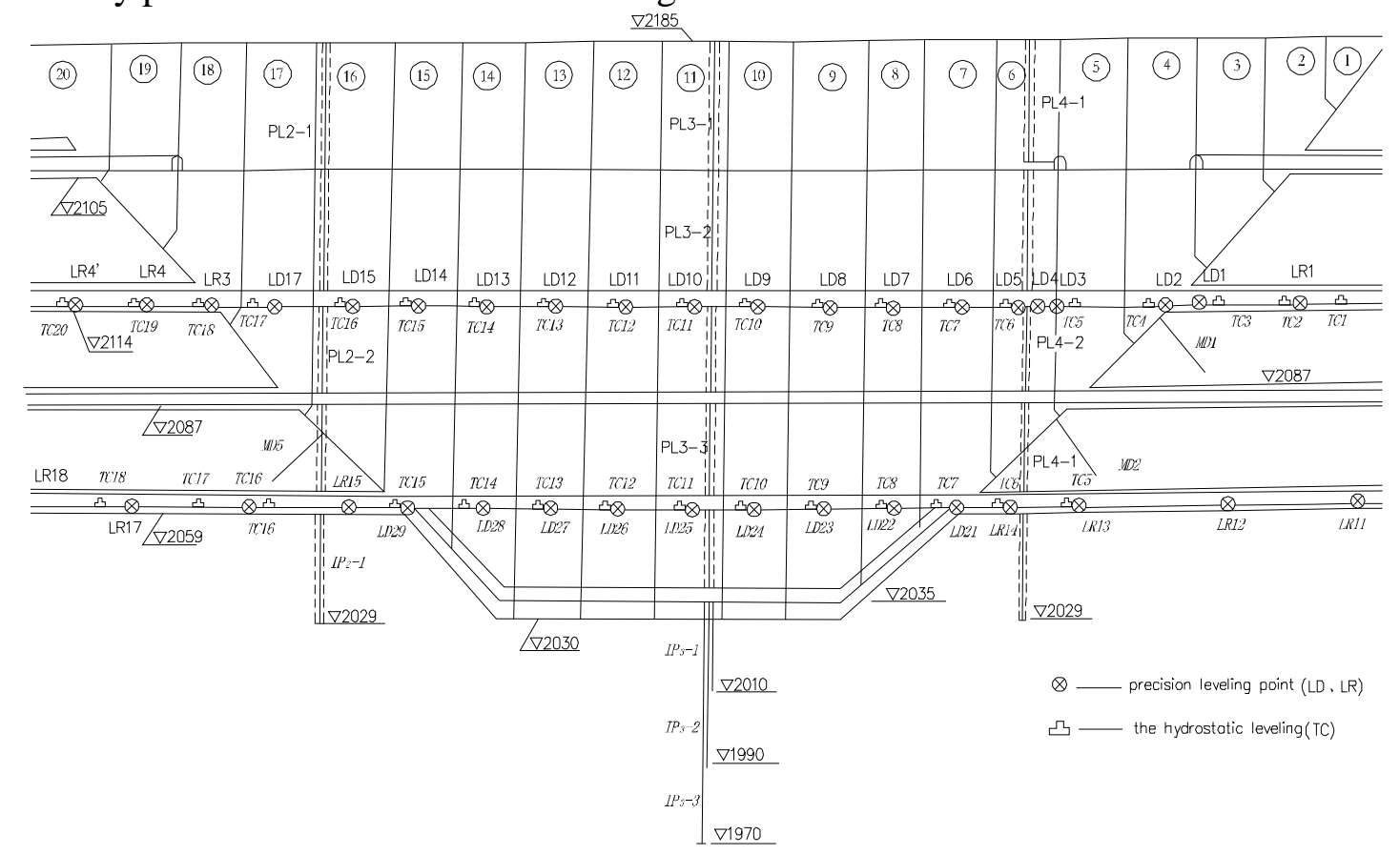

Figure 1. The survey points of deformation distribution of LiJiaxia hydropower station

According to the report of dam monitoring data analysis of LiJiaxia hydropower station, the deformation characteristics are summarized as following:

(1) The radial deformation characteristics

The radial displacement of LiJiaxia hydropower station changes periodically with the temperature. The displacement toward downstream decreases as the temperature goes up, and increases as the temperature goes down. In addition, the radial displacement changes with an obvious water level. The displacement toward downstream increases as water level goes up, and decreases as water level goes down. At the same water level, the max radial displacement measure value that induced by temperature is about $11.5 \mathrm{~mm}$, while at the same temperature, the max radial displacement measure value that induced by different water level is $12.5 \mathrm{~mm}$. Thus it's reasonable that arch dam radial displacement mainly influences mainly by the temperature. From the point of spatial distribution, the maximum radial displacement generally occurs near the dam crest in low temperature season at the load of water and decreasing temperature. While in the high temperature season,, the maximum radial displacement generally appears in 1/2 high near the dam at the load of water and increasing temperature. 
(2)The tangential deformation characteristics

The tangential displacement changes periodically with the temperature. The survey points deformation gets toward both sides as the temperature goes up, while the deformation gets toward water bed as the temperature goes down. In addition, the tangential deformation of dam body induced by water level is obvious. Due to the different geological conditions between the left and the right bank of the arch, tangential displacement is asymmetrically distributed. From the point of spatial distribution, the maximum tangential displacement and maximum amplitude influenced by the left bank of geological conditions both appear in 6 \# dam upper section.

(3) The vertical deformation characteristics

The vertical displacement of dam body changes periodically by temperature. As the temperature goes down, the concrete dam displacement measuring points shrink. As the temperature goes up, the points get up and down. Besides, the vertical displacement of dam crest is affected more easily by temperature than the other parts of dam, and the periodical change is more obvious.

The upstream water level of dam body influences the change of the vertical displacement. The site of the measurements has a certain degree of the increasing settlement, which is more obvious in the vertical dam crest displacement than the site of riverbed dam site. The higher the dam vertical displacement measuring point elevation from central part to the river, the greater the vertical displacement amplitude is.

\section{Deformation characteristics of Dong Jian hydropower station}

There are five vertical lines (L1、L3、L5、L7、L9) in the dam body of Dong Jian hydropower station to monitor the vertical displacement, the survey points of deformation distribution is shown in Figure 2.

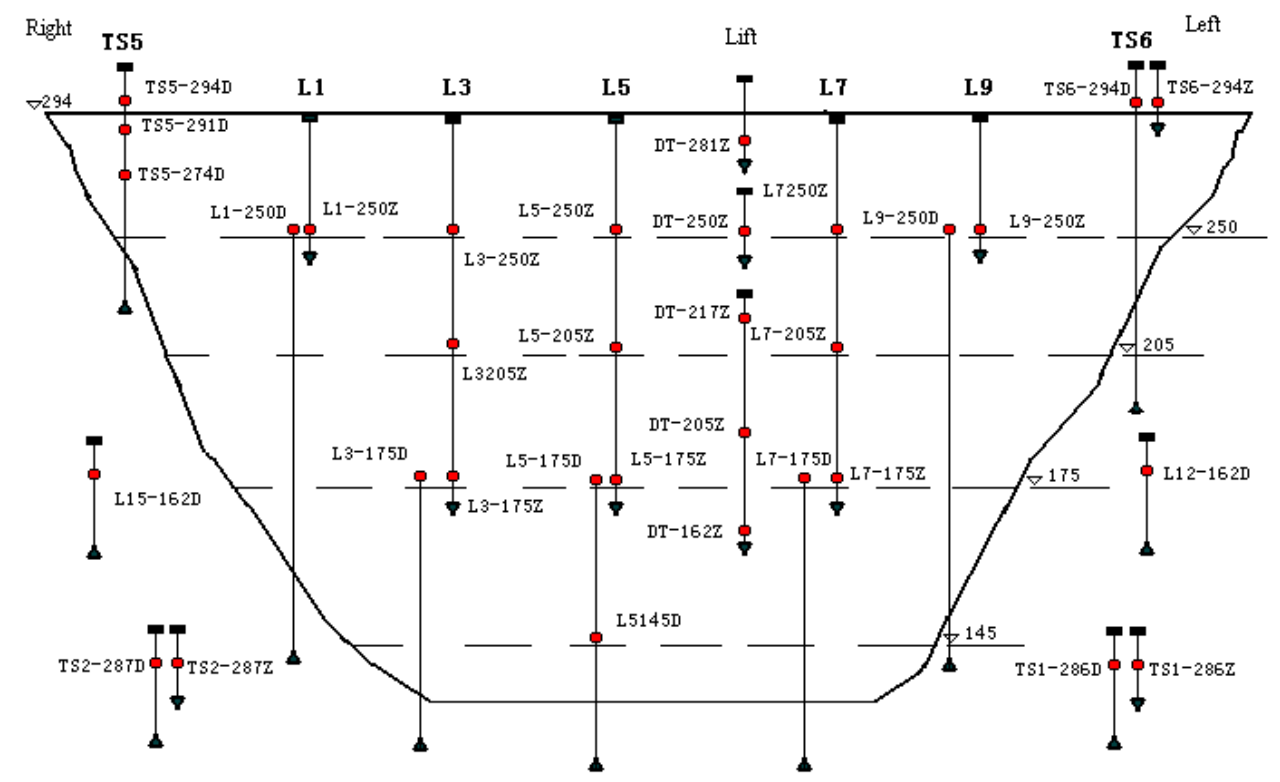

Figure 2. The survey points of deformation distribution of Dong Jian hydropower station

According to the report of dam monitoring data analysis of Dong Jian hydropower station, the deformation characteristics are summarized as following:

(1) The radial deformation characteristics

The radial displacement changes periodically with the temperature. As the temperature goes up, the dam body deforms towards upstream, and as the temperature goes down, the dam body deforms towards downstream. Besides, the radial displacement changes obviously with water level. As water level goes up, the deformation of survey points increase to the downstream. Similarly, as water level goes down, the deformation of survey points decrease to the downstream.

From the point of spatial distribution, the measuring points of the same vertical line decreases with elevation drops. The biggest change of measuring point is located on $291 \mathrm{~m}$ elevation, the second biggest change point is $250 \mathrm{~m}$ elevation, and next is $205 \mathrm{~m}$. The smallest change of measuring point is 
located on the elevation $175 \mathrm{~m}$ and $145 \mathrm{~m}$. On the same elevation, the displacement of arch crown survey point changes biggest ( 5 \# vertical line), the second is both side of the crown ( 3 \# 7 \# vertical lines), while the smallest change of survey point is located at the arch abutment (1 \# 9 \# vertical lines).

(2)The tangential deformation characteristics

Tangential displacement change is affected obviously and periodically by temperature. As temperature goes up, deformation of dam body is toward to cross-strait. As the temperature goes down, the dam deformation is toward to the riverbed. On the other hand, tangential displacement is affected by water level as well. As the upstream water level goes up, both sides of each measuring point of the deformation increases. As the upstream water level goes down, each measuring point of the deformation decrease or to the riverbed deformation on both sides.

From the point of spatial distribution, whether it is low or high temperature, the largest tangential displacement is located at the upper of dam. For example, 3 \# vertical tangential displacement of measuring point distribution shows that the dam the right half of the $205.00 \mathrm{~m}$ height tangential displacement is larger, 7 \# vertical tangential displacement of measuring point distribution shows that the left part in $250.00 \mathrm{~m}$ height of dam tangential displacement is larger.

(3) The vertical deformation characteristics

The vertical displacement is mainly affected by temperature, and the relative vertical displacement of the dam body changes periodically by temperature in certain years, of which $291 \mathrm{~m}$ elevation corridor, $205 \mathrm{~m}$ elevation corridor and $145 \mathrm{~m}$ elevation in the corridor measuring point in low temperature season, high temperature season service. The dam crest, $250 \mathrm{~m}$ elevation corridor, measuring point of the $175 \mathrm{~m}$ elevation corridor in high temperature season, season looked at low temperature. The different characteristics of the main reason is that the relative displacement of the dam vertical displacement is a measuring point displacement change and the change of the basis points are closely related, namely the base itself is also changing. The higher elevation of measuring point, the more change by temperature. Central station near the river is affected by temperature changes. The upstream change of water level has the certain influence on the relative vertical displacement of the dam body. The higher elevation of measuring points, the greater the relative vertical displacement amplitude is.

\section{Deformation characteristics of Feng Le reservoir}

There are two plumb lines, three invers plumb lines in Feng Le reservoir arch dam, as shown in Figure 3.

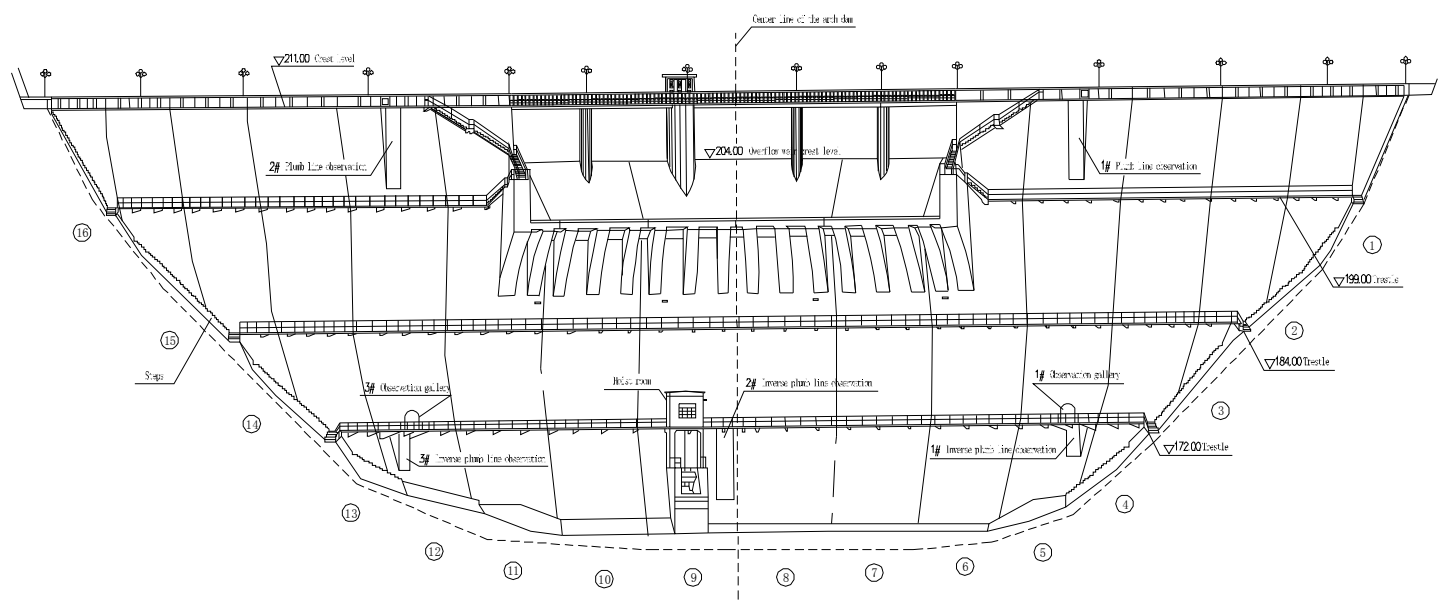

Figure 3. The survey points of deformation distribution of Feng Le reservoir arch dam

According to the report of dam monitoring data analysis of Feng Le reservoir, the deformation characteristics are summarized as following:

(1) The radial deformation characteristics

Radial horizontal displacement is mainly affected by temperature. The radial displacement dam block near the river bed is negatively correlated with temperature change, when the temperature 
measurement value decreases, and displacement of upstream, when the temperature goes down, test value increase, downstream displacement. Left and right abutment, by contrast, basic are positively correlated with temperature change, when the temperature measured values increase, downstream displacement, temperature drop when measuring value decreases, and the upstream displacement. In addition, water level change has some influence on the radial horizontal displacement of measuring points. The average water level goes up, horizontal displacement of downstream increases, and water level goes down, the horizontal displacement of the downstream decreases. Water level change along the river has influence on the horizontal displacement. From spatial distribution, the maximum radial displacement is located at the dam body upper part, and on both sides of the computation of the maximum annual luffing slightly larger than the riverbed dam section.

(2) The tangential deformation characteristics

Dam tangential displacement is significantly affected by temperature. The tangential displacement of section which is generally closed to the left bank of dam block is negative correlation with temperature. As temperature goes up, the displacement of the right bank of the measured value decreases, temperature goes down, the measured value increases, the displacement of the left bank. Close to the right bank of dam block, on the other hand, when the temperature goes up, the displacement is toward to the left bank, when the temperature goes down, the displacement is toward to the right bank. Water changes have effects on the dam tangential displacement, but affects smaller than the relative temperature. Tangential displacement amplitude and years on either side of the dam are greater than the riverbed dam section of the tangential displacement amplitude and years.

\section{Discussion}

The deformation principles of concrete arch dams are summarized by the analysis of three typical concrete arch dam deformation characteristics as following:

(1) The radial displacement changes periodically, mainly influenced by temperature. As the temperature goes up, the survey point deformations are toward to upstream. Conversely, as the temperature goes down, the survey point deformations are toward to downstream. Besides, the radial displacement changes obviously with water level. As water level goes up, the survey point deformation is toward to downstream. And as water level goes down, the survey point deformation is toward to upstream.

(2) From the space distribution of radial displacement, under the circumstance of water level and decreasing temperature in low season, the maximum value of radial displacement appears near the dam crest. While under the circumstance of water level and increasing temperature in high season, the maximum value of radial appears at the half of dam height.

(3) Tangential displacement is affected obviously and periodically by temperature. As the temperature goes up, the deformation of the point is toward to both river sides. And as temperature goes down, the deformation of the points is toward to the riverbed. Besides, dam tangential displacement affected by water level change is more obvious. As the water level goes up, the dam has the trend of river bed deformation. On both sides of the dam section of the tangential displacement is greater than the riverbed dam displacement. When the left and the right bank of the arch, and geological conditions of the two sides have differences, the tangential displacement change is asymmetrical distribution.

(4) The dam vertical displacement is mainly affected by temperature change, and has a certain cyclical changes. As the temperature goes down, concrete dam shrinkage measuring points sink, as the temperature goes up, the points of subsidence decrease. At the same time, the vertical displacement of dam crest is affected by temperature than the other parts, and measurement of the periodic change is more obvious. In addition, the upstream water level of dam body is of certain influence on the change of the vertical displacement, which is located in the vertical displacement amplitude than the site of riverbed dam site which is located in on both sides of the measuring point. The higher the dam vertical 
displacement measuring point elevation of central near the river, the greater the vertical displacement amplitude is.

(5) The maximum vertical displacement of concrete arch dam is 6-12 times smaller than the radial displacement.

\section{Summary}

Based on the analysis and summery of concrete arch dam deformation, some further understandings of determination of deformation monitoring index of concrete arch dam are made as following:

The surveying points of dam crest are significantly monitored as key deformation area in low temperature season, while the survey points that located at the half of dam height are chose to be important controlling area in high temperature season.

Dam section that located at the center of riverbed should be the main part of monitoring index of radial displacement. Besides, dam section that located at both sides of river should be the main part of monitoring index of tangential displacement.

The monitoring index of vertical displacement of arch dam can be flexibly selected because of small differential settlements.

\section{Acknowledgements}

This work was supported by Dam Safety Management Center of Ministry of Water Resources of China and Hydraulic Engineering in Nanjing Hydraulic Research Institute. This research was also supported by National Natural Science Foundation of China (51209143) and the Special Fund for Public Welfare Industry of Ministry of Water Resources of China (201501033). The opinions, findings and conclusions or recommendations expressed in this paper are those of the authors.

\section{References}

[1] Liu H W. On drafting of dam safety monitoring index. The Chinese journal of Yangtzi River, Volume 30, Issue 7, pp 35-37 (1999).

[2] Zhang Y T. Analysis on several catastrophic failures of hydraulic projects in view of rock hydraulics. The Chinese journal of hydraulic engineering, Volume 22, Issue 5, pp 1-10 (2003).

[3] Wei D R. On working out dam safety monitoring index. The Chinese journal of dam and safety, Volume 19, Issue 6, pp 24-28 (2003).

[4] Gu C S, Wu Z R, Yang W. Determining grade three monitoring indicator of dam deformation with structural analysis method, The Chinese journal of Hohai University, Volume 28, Issue 5, pp 7-10 (2000).

[5] Geng K Q, Wu Y P, Bao Y J. The investigation of deformation process anomalous characteristics for arch dam and its abutments built on complex rock foundation. The Chinese journal of hydraulic engineering, Volume 18, Issue 4, pp 41-48 (1995).

[6] Wu Z R. Beijing High Education Press, Safety monitoring theory and its application of hydraulic structures: 213-222 (2003).

[7] $\mathrm{Gu} \mathrm{C} \mathrm{S}, \mathrm{Wu} \mathrm{Z} \mathrm{R}$. Nanjing Hohai University Press. Safety monitoring of dams and dam foundations-theories, methods and their application: 213-234 (2006).

[8] Li Z Z. Safety monitoring index of concrete dam in operation. The Chinese journal of dam and safety, Volume 6, Issue 2, pp 14-31 (1992).

[9] Wang D H, Zhao Q L. Safety monitoring and forecasting model test of Gezhouba Water Control Project. The Chinese journal of Yangtzi River, Volume 21, Issue 3, pp 10-17 (1985).

[10] Zheng D J, Liu G S, Gu C S. A combination formulation of monitoring index of dam horizontal displacement. The Chinese journal of hydropower automation and dam monitoring, Volume 26, Issue 2, pp 42-44 (2002). 
[11] Shen Z Z. Hohai University doctoral thesis. The three gorges dam and the bedrock deformation analysis during the construction and its inverse analysis model:24-69 (1995).

[12] Gu C S, Zheng D J. Nanjing Hohai University. Dam safety data analysis report of Li Jiaxia hydropower station:12-50 (2007).

[13] Gu C S, Bao T F, Wang J, et al. Nanjing Hohai University. Dam safety data analysis report of Dongjian hydropower station in Hunan province:21-65 (2007).

[14] Gu C S, Zheng D J. Nanjing Hohai University. Dam safety data analysis report of Fengle reservoir in huangshang, Anhui province:1-62 (2002). 